5. Васильева М., Камфер Ю., Степанова О. Внешний и внутренний аудит на предприятии. "Экономикоправовой бюллетень", 2001.

6. Дмитриева, И.М. Бухгалтерский учет и аудит: учебное пособие / И.М. Дмитриева. - М.: ФБК - ПРЕСС. 2015. - $368 \mathrm{c}$.

7. В.А. Ерофеева, В.А. Пискунов, Т.А. Битюкова. Аудит -М: Юрайт, 2013

8. Сорокина, Н.А. Аудит: теория и хозяйственные ситуации: практическое руководство / Н.А. Сорокина. Хабаровск: Прогресс. - 2015. - 218 с.

9. Филипьев Д.Ю. Внутренний аудит: мифы и реальность / Учет и контроль. - М.: Финансы. - 2007. - №1.

10. Хорохордин Н.Н. Служба внутреннего аудита: этапы создания, цели и задачи // Аудиторские ведомости. 2007. - № 10.

11. https://iia-ru.ru/inner_auditor/issledovania/

\title{
Зверева Е.В. \\ Территориальное регулирование занятости населения как инструмент эффективной региональной политики
}

Петербургский государственный университет путей сообщзения Императора Александра I doi: 10.18411/trnio-10-2021-142

(Россия, Санкт-Петербург)

\section{Аннотация}

В исследовании предложен подход, суть которого заключается в необходимости выделения территориально-хозяйственных образований для регулирования занятости населения, ибо регион выступает не как единый монолит, а как синтез районов с различными специфическими особенностями занятости населения, интересами и приоритетами развития. В рамках данной проблемы весьма значимым становится определение направлений регулирования занятости населения в регионе с учетом специфики его отдельных территориально-хозяйственных образований. Предложены основные направления регулирования занятости населения в территориально-хозяйственных образованиях с узкопрофильной специализацией хозяйства при реализации региональной политики.

Ключевые слова: регион, занятость населения, региональная политика, регулирование занятости населения, государственное регулирование занятости населения, территориально-хозяйственное образование, узкопрофильная специализация хозяйства, механизм регулирования занятости населения.

\section{Abstract}

The study proposed an approach, the essence of which is the need to allocate territorialeconomic entities to regulate the employment of the population, for the region does not act as a single monolith, but as synthesis of areas with various specific peculiarities of employment, interests and priorities of development. Within the framework of this problem, the determination of the areas of employment regulation in the region, taking into account the specifics of its individual territorial economic entities, becomes very significant. The main directions for regulating the employment of the population in the territorial and economic entities with the narrow-profile specialization of the economy in the implementation of regional policies are proposed.

Keywords: region, employment of the population, regional policies, regulation of employment of the population, state regulation of employment of the population, territorial and economic education, a narrow-profile specialization of the economy, the mechanism for regulating the employment of the population.

Необходимость регулирования занятости населения исходит из особенностей национальной и региональной экономической политики, так как занятость важным и значимым объектом регулирования со стороны государства, от которой зависит экономический рост. Высокая значимость государственного регулирования обусловлена тем, что государство обеспечивает определенность и целостность территориального пространства 
хозяйствования, а для Хабаровского края в целом и составляющих его территорий возрастает актуальность по причине слабой заселенности. Состояние в сфере занятости региона определяется природными, экономическими, социальными и другими факторами, что указывается во многих исследованиях по проблемам занятости населения. Однако при этом не учитываются внутренняя территориальная дифференциация, экономическая и социальная проблемность входящих в него территорий.

Хабаровский край выполняет задачи федерального и регионального уровней. Территория Хабаровского края неоднородна в силу ее внутрирегиональных различий, так как ее большая протяженность с севера на юг предопределила различие в природноклиматических условиях и ресурсах. Хабаровский край, как субъект Федерации имеет в своем составе административно-территориальные районы, выполняющие определенные функции и задачи, отличающиеся друг от друга особенностями: экономико-географического и геополитического положения, историческим ходом освоения территории, природноклиматическими, степенью освоенности и заселенности, демографическими, социальноэкономическими и др. Условия экономического развития и проживания населения по районам Хабаровского края резко дифференцированы. Северные районы края отличны от других суровым климатом, многолетней мерзлотой, сложностью рельефа, неодинаковым составом природных ресурсов. В крае выделяются территории, отнесенные к районам Крайнего Севера. Особенности природно-климатических условий и ресурсного потенциала определили неодинаковую степень заселенности районов края. Важное место в развитии их экономики, хозяйственного освоения и занятости занимает слаборазвитая транспортная инфраструктура (в этих районах отсутствуют или слабо развиты железнодорожный транспорт, автомобильный и др.). Это накладывает свой отпечаток, во-первых, на степень заселенности; вовторых, на концентрацию и уровень развития промышленности; в-третьих, на отраслевую моноспециализацию, которая носит очаговый характер и, влияющая, в свою очередь, на заселенность, уровень урбанизации и уровень жизни населения. Заселение и производство Хабаровского края сконцентировано преимущественно в центральных и южных районах, благоприятных по географическим, природно-климатическим и транспортным условиям. Для этих районов характерно размещение практически всех отраслей экономики (преимущественно обрабатывающих), железных дорог, портов и крупных городов.

Наиболее плотно заселена его южная часть, наименее плотно северная. Северные ТХО (Охотский, Аяно-Майский, Тугуро-Чумиканский, им. П. Осипенко, Ульчский), занимающие $60 \%$ от всей территории Хабаровского края и сосредотачивающие лишь $20 \%$ всего населения края, отличаются слабой заселенностью, что оказывает влияние на состояние и развитие экономики края. Национально-этнический состав населения края представлен более чем 30 национальностями, имеющим свои обычаи и традиции, что, безусловно, отразилось на территориальной специфике занятости. В местах проживания коренных малочисленных народов Севера около 19 малых народностей с численностью 18,3 тыс. чел. (нанайцы, эвенки, ульчи, нивхи, эвены и др.). В северных районах края расположены, в основном, населенные пункты, которые исторически сформировались вблизи районов добычи сырья. В центральных и южных районах Хабаровского края сосредоточено 80\% населения, которое проживает преимущественно в городах и сельской местности. Внутрирегиональные особенности занятости населения вызвали необходимость классификации, то есть объединения районов края в определенные группы по сходной специализации хозяйства и занятости в профессионально-квалификационном и гендерном соотношении.

Необходимость усиления государственного регулирования занятости населения обусловлена ростом значимости регионального аспекта развития экономики. Существующее в настоящее время деление региона на муниципальные образования усложняет процесс регулирования занятости населения. В исследовании предложен подход, суть которого заключается в необходимости выделения территориально-хозяйственных образований для регулирования занятости населения, ибо регион выступает не как единый монолит, а как 
синтез районов с различными специфическими особенностями занятости населения, интересами и приоритетами развития. В рамках данной проблемы весьма значимым становится определение направлений регулирования занятости населения в регионе с учетом специфики его отдельных территориально-хозяйственных образований. Выделение территориально-хозяйственных образований (далее именуем ТХО) в регионе обосновано существованием значительной внутрирегиональной дифференциации, характеризующейся широким диапазоном признаков природно-климатических, национальных, демографических, социально-экономических и др. [1].

В связи с этим обстоятельством, типологизация ТХО играет огромное значение не только для анализа социально-экономического положения региона, но и для реализации региональной политики по вопросам регулирования занятости населения. Методы, механизмы и мероприятия политики занятости должны учитывать особенности типов ТХО, выделяемых с учетом экономических, социальных, природных, геополитических и иных существенных условий.

Таким образом, ТХО рассматривается с точки зрения подхода к регулированию занятости населения в регионе и представляет собой часть территории региона, объединяющую районы края по принципу смежности, хозяйственной специализации и структуре занятости, развивающуюся на собственной экономической базе и общности интересов [1]. В то же время, ТХО определяет пространственную среду и не является новым административным образованием. Развитие экономики региона и его ТХО определяется особенностями: экономико-географического и геополитического положения; природноклиматическими условиями и ресурсами; степенью освоенности и заселенности; общеэкономической ситуацией; структурными преобразованиями экономики как региона, так и районов в него входящих.

Внутрирегиональные различия края по природно-климатическим, демографическим особенностям, специализации, структуре занятости отразили необходимость их типологизации. Данные ТХО различаются по особенностям экономико-географического положения, степени заселенности, природно-ресурсному потенциалу, концентрации промышленного производства, развитию транспортной инфраструктуры, уровню социальноэкономического развития, территориальной структуре хозяйства, структуре занятости (по полу, возрасту, уровню образования, профессионально-квалификационным характеристикам) и др. Различия этих условий становятся причиной территориальных диспропорций состояния рынков труда ТХО.

Выделение в регионе ТХО вызывает необходимость их исследования относительно специфики регулирования занятости населения. Данный подход к регулированию занятости населения в ТХО позволяет конкретизировать мероприятия по обеспечению эффективной занятости, используя определенные формы и методы, учитывающие особенности конъюнктуры регионального рынка труда. Механизм регулирования занятости населения в регионе предполагает рассмотрение его с позиций действия и использования не только в регионе, но и его территориально-хозяйственных образованиях. Разработка механизма регулирования связана с тем, что его действия должны распространяться на регион и на территориально-хозяйственные образования, входящие в его состав. Механизм регулирования занятости населения должен учитывать изменяющиеся процессы в экономике при выборе соответствующей политики занятости, адаптировав ее применительно к модели развития общества, условиям и особенностям развития региона [2].

Таким образом, механизм регулирования занятости населения предполагает использование нормативно-правовых, экономических, социальных, демографических, институциональных и других методов, которые способствуют сбалансированности рынка труда и обеспечению эффективной занятости. Они применяются в зависимости от складывающейся социально-экономической и демографической ситуации в Хабаровском крае и его ТХО. Причем выбор того или иного метода определяется необходимостью 
решения конкретных стратегических и тактических задач, стоящих перед регионом в области регулирования занятости населения.

1. Зверева Е.В. Механизм регулирования занятости населения в регионе и его территориально-хозяйственных образованиях // Проблемы управления экономикой в трансформируемом обществе: Сборник статей Всероссийской научно-практической конференции. - Пенза: Изд-во Приволжский Дом знаний, 2004. С. 187189.

2. Зверева Е.В., Шайкина Л.К. К вопросу о формировании региональной модели регулирования занятости населения в теоретико-экономическом наследии различных концепций и школ // Научно-теоретический журнал «Социальные и гуманитарные науки на Дальнем Востоке». T. XVII. Вып. 1, 2020. - С. 225 - 230.

\section{Измалкова И.В., Кащеева О.М., Вереникина Ю.С. Финансовый анализ предприятия с целью обнаружения признаков банкротства}

Финансовый университет при Правительстве РФ (Россия, Липечк)

doi: 10.18411/trnio-10-2021-143

\section{Аннотация}

В статье рассмотрены признаки, указывающие на вероятность банкротства предприятия в обозримой перспективе, а также раскрыты этапы финансового анализа, который проводится для обнаружения данных признаков.

Ключевые слова: предприятие, банкротство, признаки банкротства, финансовый анализ, предбанкротное состояние.

\section{Abstract}

The article examines the signs that indicate the likelihood of bankruptcy of an enterprise in the foreseeable future, and also discloses the stages of financial analysis, which is carried out to detect these signs.

Keywords: enterprise, bankruptcy, signs of bankruptcy, financial analysis, pre-bankruptcy.

Предпринимательство сегодня характеризуется двумя основными направлениями деятельности - хозяйственной и финансовой, которые направлены на достижение главной цели экономического субъекта достижение прибыли в соответствие с его миссией, определяемой собственниками. Однако, в связи с тем, что в российской экономике существуют кризисные явления и нестабильность, многие экономические субъекты сталкиваются с финансовыми проблемами. При недостаточном внимании такого рода проблемам им может грозить банкротство. В общем смысле под банкротством понимается состояние, при котором предприятие не может платить по своим обязательствам кредиторам и поддерживать нормальную деятельность как экономического субъекта. Любое предприятие может столкнуться с проблемой неустойчивого финансового состояния, неплатежеспособностью, банкротством. В свою очередь, своевременное выявление признаков потенциальных финансовых затруднений в обозримой перспективе может дать шанс выработать эффективные управленческие решения, направленные на избежание банкротства [4, с. 38].

Банкротство может возникнуть как в связи с влиянием внешних, так и внутренних факторов. В частности, к внешним факторам могут быть отнесены введение новых экономических санкций со стороны других стран по отношению к России, международные политические конфликты и др. Внутренние факторы, которые могут привести предприятие к банкротству, многообразны, но А.Д. Шеремет к важнейшим из них относит неэффективные управленческие решения со стороны руководства, которые, в свою очередь, приводят к таким явлениям, как недостаток собственного оборотного капитала, рост дебиторской задолженности, сокращение выручки и др. [5, с. 135]. 